Artigo

\title{
A Parceria Entre Poder Público e Instituições Não Governamentais na Implementação de Programas Sociais: análise do Programa Projovem no município de Contagem - MG - Brasil
}

Partnership Between Public Authorities And Non-Governmental Institutions In The Implementation of Social Programs: analysis Projovem Program in the city Contagem

$$
\text { - MG - Brazil }
$$

Asociación Entre Autoridades Públicas y No Gubernamentales Instituciones en la Implementación de Programas Sociales: aálises del programa Projovem en la ciudad Contagem - MG - Brasil

\footnotetext{
${ }^{1}$ Filiação institucional. Possui graduação em Serviço Social e mestrado em Ciências Sociais pela Pontifícia Universidade Católica de Minas Gerais e especialização em Políticas Públicas e em Projetos Sociais em áreas urbanas pela Universidade Federal de Minas Gerais. É docente na Faculdade de Políticas Públicas da Universidade Estadual de Minas Gerais - Belo Horizonte, MG, Brasil.

Correspondência:

E-mail: camilaasdiniz@yahoo.com.br
} 
Resumo

Esse trabalho se insere no âmbito dos estudos sobre as políticas sociais descentralizadas no Brasil atual, considerando as relações intergovernamentais, e em específico, entre os governos federal e local no contexto do modelo de gestão social adotado a partir dos anos de 1990. Com o propósito de examinar as relações entre instituições do terceiro setor e governo municipal na execução compartilhada de programas sociais, este trabalho apresenta um estudo de caso referente ao Programa Projovem Adolescente, executado no município de Contagem - Minas Gerais, propondo uma reflexão sobre a relação estabelecidas entre poder local e a sociedade civil. Inicialmente se propõe a realizar um estudo bibliográfico sobre o conceito de políticas públicas e políticas sociais, fazendo um recorte histórico sobre as políticas de juventude no Brasil e os atores envolvidos em sua implementação. Subsequente apresenta o conceito de implementação de políticas públicas, e propõe uma reflexão sobre o modelo político vigente, trazendo uma perspectiva de identificar os atores envolvidos e suas funcionalidades. Posteriormente traz uma reflexão acerca do conceito de gestão social e gestão compartilhada, entendido neste trabalho como as relações de governança estabelecidas entre os entes federados e atores da sociedade civil na execução de políticas públicas. O trabalho empírico incluiu o uso de entrevistas semiestruturadas com gestores municipais, gestores das instituições não governamentais executoras do programa e técnicos sociais governamentais que atuam nos Centros de Referência da Assistência Social. O trabalho apresenta em suas considerações finais as fragilidades e ausências existentes na interação entre o governo local e as instituições executoras não governamentais no processo de implementação e de gestão de políticas públicas, considerando que esta relação está longe de ser virtuosa, como propõe a literatura e com gargalos pautados pelos critérios da legislação brasileira.

Palabras Clave: Políticas Públicas, Políticas Sociais, Gestão Pública, Terceiro Setor, Juventude.

\section{Abstract}

This work falls within the scope of the studies on decentralized social policies in Brazil today, considering the intergovernmental relations, and in particular, between the federal and local governments in the context of social management model adopted from the year 1990. In order to examine the relationship between institutions of the third sector and local government in the shared implementation of social programs, this work presents a case study of the Projovem Adolescent Program, implemented in the municipality of Contagem - Minas Gerais, proposing a reflection on the relationship established between power Local and civil society. Initially it is proposed to carry out a bibliographical study on the concept of public policies and social policies, making a historical portrait of youth policies in Brazil and the actors involved in its implementation. Subsequent introduces the concept of implementation of public policies, and proposes a reflection on the current political model, bringing a perspective of identifying the actors involved and their features. Later offers reflection about the concept of social management and shared 
management, understood here as the governance of relations between federal agencies and civil society actors in the implementation of public policies. The empirical work included the use of semi-structured interviews with municipal managers, managers of non-governmental institutions executing the government social program and technicians who work in the Reference Centers of Social Assistance. The work presents in his closing remarks the existing weaknesses and absences in the interaction between local government and non-governmental executing agencies in the implementation process and policy management, considering that this relationship is far from being virtuous, as proposed by the literature and with guided bottlenecks by the criteria of the Brazilian legislation.

Keywords: Public Policy, Social Policies, Public Management, Third Sector, Youth.

Resumen

Este trabajo se inscribe en el ámbito de los estudios sobre las políticas sociales descentralizadas en el Brasil de hoy, teniendo en cuenta las relaciones intergubernamentales y, en particular, entre los gobiernos federal y locales en el contexto del modelo de gestión social adoptada desde el año 1990. Con el fin para examinar la relación entre las instituciones del tercer sector y el gobierno local en la aplicación común de los programas sociales, este trabajo presenta un estudio de caso del Programa de Adolescentes Projovem, implementado en el municipio de Contagem - Minas Gerais, que propone una reflexión sobre la relación que se establece entre el poder La sociedad local y civil. Inicialmente se propone llevar a cabo un estudio bibliográfico sobre el concepto de las políticas públicas y las políticas sociales, haciendo un retrato histórico de las políticas de juventud en Brasil y los actores involucrados en su implementación. Con posterioridad introduce el concepto de implementación de políticas públicas, y propone una reflexión sobre el modelo político actual, aportando una perspectiva de la identificación de los actores involucrados y sus características. Más tarde ofrece la reflexión sobre el concepto de la gestión social y la gestión compartida, entendida aquí como la regulación de las relaciones entre las agencias federales y los actores de la sociedad civil en la implementación de políticas públicas. El trabajo empírico incluido el uso de entrevistas semiestructuradas con los gestores municipales, gestores de instituciones no gubernamentales que ejecutan el programa social del gobierno y técnicos que trabajan en los Centros de Referencia de Asistencia Social. El trabajo presenta en su discurso de clausura de las debilidades y ausencias existentes en la interacción entre el gobierno y no gubernamentales agencias ejecutoras locales en la gestión de procesos y aplicación de políticas, teniendo en cuenta que esta relación está lejos de ser virtuoso, según lo propuesto por la literatura y con los cuellos de botella guiados por los criterios de la legislación brasileña.

Palavras-chave: Políticas Públicas, Políticas Sociales, Gestión Pública, 
Tercer Sector, Juventud.

\section{Breve Contextualização Sobre a Gestão das Políticas Públicas na Década de 1990}

A reforma do Estado faz parte da agenda política nacional e internacional dos anos 90. Transformações de ordem econômica, política e a dinâmica tecnológica condicionaram a reforma dos aparelhos de Estado no mundo. A queda no crescimento da economia, o acirramento da crise fiscal e o descontrole inflacionário característico dos anos 70 constituíram os sintomas mais aparentes do esgotamento do modelo de desenvolvimento baseado no Modelo de Bem Social - "Welfare State" para o Estado Mínimo.

No mesmo período, o Brasil vivia um contexto de industrialização e de acelerada urbanização. Os anos 70 caracterizavam-se simultaneamente pelo aumento das demandas por serviços públicos e pela transformação da base produtiva com a introdução da microeletrônica no parque industrial brasileiro. A mudança na base tecnológica é acompanhada de novas exigências quanto ao perfil da mão- de- obra. A seleção de pessoal qualificado impulsiona o crescimento da classe média, iniciado nos anos 30. Por outro lado, a simplificação de processos de trabalho e a automação de funções levam à dispensa de mão-de-obra, ocasionando maior concorrência por postos de trabalho.

A unificação, uniformização e centralização da política de previdência social, neste período, retira os trabalhadores da gestão da previdência que passa a ser tratada como questão técnica e atuarial. Observa-se por meio das autoras citadas acima, que há um grande empenho por este modelo na institucionalização da previdência e da saúde e em menor importância, da assistência social, considerando que esta somente será incorporada a seguridade social como direito a partir de 1988. Neste período, a implementação de ações no âmbito da assistência social restringiam-se às realizadas por rede conveniada e por serviços prestados pela LBA (Legião Brasileira de Assistência). A busca por outras formas de ação do estado já começa a ser incorporada por este modelo estatal, entretanto, ressalta-se que mesmo com a ampliação dos acessos públicos e privado, milhões de pessoas permaneciam fora do complexo assistencial industrial tecnocrático proposto pelo governo militar.

Os anos subsequentes a estes, serão marcados pela abertura lenta e gradual do regime, num processo de transição para a democracia, condicionando e muito a adesão brasileira às orientações conservadores neoliberais, já em curso 
em nível mundial, implicando o caráter tardio da adesão brasileira ao neoliberalismo. (BEHRING e BOSCHETTI, 2008).

O maior avanço identificado nesse período é a promulgação da Constituição Federal em 1988 num reconhecimento da igualdade entre os indivíduos e da garantia de direitos no contexto da organização política. A partir daí, a organização das políticas sociais brasileiras é impulsionada como estratégia para enfrentar a temática da desigualdade, central no debate político das sociedades modernas. Os novos parâmetros de gestão de políticas públicas, propostas pela Constituição Brasileira, possibilitaram um novo modelo de execução das políticas públicas, direcionando a gestão e transferindo a responsabilidade sobre a política de governo nacional para as esferas subnacionais e outros atores políticos. (SOUZA, 2007).

Neste novo cenário, o poder político passa a ser descentralizado para os governos locais (municípios), governos estaduais, sendo o poder Federal responsável por esta transferência de autonomia, resultando em mudanças no desenvolvimento e execução das políticas públicas brasileiras.

Segundo SOUZA (2008) o termo descentralizar significa a dispersão o a distribuição de poder que estava anteriormente concentrado no centro. Desta forma a descentralização das políticas públicas, significa uma transferência das questões administrativas, políticas que envolve outros atores e espaços territoriais. No processo de descentralização, SOUZA (2008) afirma que envolve várias instâncias, no qual enfatiza a questão da Reforma do Estado ou a forma de atuação dos governos, no qual a organização do processo de descentralização muda da esfera central do governo nacional para as esferas subnacionais, ou seja, a transferência de poder para o poder municipal e estadual.

O conceito de descentralização, segundo ARRETCHE (1999) implica a existência de uma pluralidade de níveis de decisão autônoma por parte das instituições, independentemente do poder central. O conceito aponta para a nova relação entre Estado e sociedade civil, cuja estratégia centra-se na perspectiva de cidadania, à medida que implica mudanças na estrutura do Estado, contribui para a formação de novos espaços institucionais de participação e deliberação popular e propõe a gestão conjunta das políticas públicas. (ABRUCIO,1996)

Desta forma o processo de descentralização, pode ser tratado como um processo de redistribuição do poder, tanto da esfera federal para a estadual e municipal, quanto do Estado para a sociedade. Dentre este processo de redistribuição de poder está a municipalização, em que o município seria dotado de autonomia relativa para elaborar, executar e gerir políticas que atendam com mais eficiência, agilidade e qualidade demandas e necessidades locais, tornandose mais próximas de seus beneficiários diretos. 


\section{O Processo de Implementação de Políticas Públicas no Cenário da Descentralização: compartilhando as ações no novo paradigma da gestão social}

Nesta estrutura, o distanciamento do Estado da produção direta de bens e serviços das políticas sociais pode ser marcada como um retrocesso. Por outro lado, a sua substituição pelo terceiro setor nos remete a uma reflexão no que tange a ampliação da sociedade civil em hábitos de auto-regulação e fortalecimento da capacidade da sociedade para responder de forma autônoma os problemas de interesse comum, uma vez que este papel estratégico será desempenhado por instituições representadas por pessoas da sociedade civil.

Apenas o reconhecimento de novos agentes na execução das políticas púbicas não é suficiente para dar conta da complexidade que demanda um modelo de Gestão Pública que busca o aperfeiçoamento do anterior. Tenório (1998) apresenta como proposição para o novo modelo de gestão uma mudança de ótica, que supere a linearidade perpetuada Estado-sociedade. Há consenso entre alguns autores em nomear esse novo modelo como "gestão social".

Na década de 90, com o Plano de Reforma do Estado Brasileiro, um novo modelo de Gestão Pública toma forma. A partir daí a execução e implementação de ações de políticas sociais por atores privados passam a ser uma prática normativa e contínua, estabelecida nos desenhos das políticas, que consideram a questão da "publicização", ou seja, as formas de execução de serviços públicos sociais através de instituições conveniadas com o poder público. As instituições não governamentais começam a fazer parte do sistema de serviços ofertados pelo governo, permitindo que atores políticos não governamentais estejam incluídos na organização das políticas públicas brasileiras, principalmente pela política de assistência social, que abre as portas às "parcerias" no processo de implementação de políticas públicas. (Grau e Bresser Pereira, 1998). É nesse contexto que surgem novas relações com a sociedade civil e cresce a importância das organizações não governamentais tanto na oferta dos serviços, quanto no controle social sobre a ação governamental.

Na década de 90, a gestão compartilhada passa a ser considerada uma prática contínua para os governos locais, e de certa forma, se tornando "braços" para os entes federados na execução de suas ações governamentais, utilizado espaços e mão de obra não pública na operacionalização das políticas. Os espaços privados começam a fazer parte do sistema de serviços ofertados pelo governo, permitindo que atores políticos não governamentais, estejam incluídos na organização política brasileira.

Este conjunto de associações e organizações recebe uma variedade de nomes e definições, tais como: terceiro setor, setor não governamental setor sem 
fins lucrativos. Evidencia-se, nesse período, um investimento na terceirização das atividades de responsabilidade estatal, no qual Bresser Pereira (1996) caracteriza como setor público não estatal, em que seus interesses são o interesse público e que formam parte do aparato do Estado.

A descentralização traz uma valorização do poder local, chamado por Abrucio (1996) de municipalização, representando um novo molde de representação da gestão pública contemporânea. Entretanto este fator desconsidera as capacidades específicas e exigidas a cada município como condições internas necessárias ao aparato estatal e a capacidade política, conforme Repetto citado por Filgueiras e Caetano (2008) descreve: a capacidade administrativa e política dos governos locais envolvendo a atuação e exercício da autoridade social, fatores organizativos e procedimentos técnicos, desenvolvimento de recursos humanos, habilidades para formular e coordenar políticas e programas.

Farah (2006) afirma que houve transformações no curso da esfera local de governo, a partir do processo de descentralização, chamando a atenção para a ampliação no número de atores envolvidos na formulação, controle e com destaque na implementação das políticas públicas, através do estabelecimento de parcerias - entre Estado e sociedade e entre organizações do próprio Estado, com vistas à provisão de serviços públicos e para a formulação e implementação de políticas.

Carvalho (2003) confirma Pereira (2008) quando atribui ao conceito de politica pública o significado de uma ação coletiva desenvolvida pelo ente direto, com o objetivo de concretizar os direitos sociais demandados pela sociedade e previstos em lei. Este termo é qualificado como um comprometimento do Estado diante de uma determinada sociedade, lembrando-se sempre que as políticas públicas efetivam os direitos sociais garantidos e declarados em Lei. Se constituem como espaços centrais de mediação e de gestão dos conflitos sociais no contexto das sociedades contemporâneas - complexas, plurais e diferenciadas, ou seja, resultam da atividade política, em campos ou arenas especificas, dos diferentes atores sócio políticos que, a partir de suas demandas, pressões e atuações, procuram influir na formação da agenda.

A fim de conservar o foco no tema do nosso trabalho, vamos tratar especificamente das políticas sociais. Segundo Fleury (2005) o conceito de política social, ainda que seja delimitado pelas ações públicas, governamentais ou não, destinadas a proporcionar respostas às demandas que têm origem no processo de reprodução dos indivíduos.

A ação de descentralização pode favorecer o reconhecimento da diversidade das realidades de implementação, entretanto, a partir das leituras realizadas, ainda não percebemos que esta oferta está associada à integralidade de atores sociais envolvidos e nem a uma renegociação do pacto social que deveria ser estabelecido entre estes atores sociais na definição clara de seus 
papéis. É nesse processo que o processo de gestão compartilhada se inicia, pois há mudanças de responsabilidades, definida por SOUZA (2008), onde governo e organizações não governamentais atuam na execução e desenvolvimento de políticas sociais, neste caso utilizando o termo de SOUZA (2008) de Governança de Múltiplo Nível.

Pierre \& Stoker (2000), afirmam que as ações de governança em vários níveis, são compreendidas como o desenvolvimento de ações que tornem o Estado um "facilitador", no qual a ações pro- ativas da sociedade se integram ao conjunto de meios para o cumprimento de metas e ações públicas. A definição de base de governação a vários níveis, conceito puro do termo de Pierre \& Stoker (2000), se refere à negociação, não-hierárquica e as mudanças entre instituições a nível transnacional, nacional, regional e local, significa uma compreensão das relações intergovernamentais.

Nesta perspectiva Odrioloza (2009) afirma que o papel do terceiro setor ou o espaço público não estatal, progressivamente desempenha uma prestação e gestão dos serviços sociais públicos em uma grande variedade de países, são abundantes os argumentos que permeiam as virtudes da participação da sociedade civil na gestão direta de políticas públicas.

\section{A Gestão Compartilhada das Políticas de Juventude}

A juventude se inscreve como questão social no mundo contemporâneo, a partir de duas abordagens principais, tais como afirmam CASTRO E AQUINO (2008). De um lado, por meio dos "problemas" comumente associados aos jovens (como a delinqüência, o comportamento de risco e a drogadição, entre outros), e de outro que demandariam medidas de enfrentamento por parte da sociedade, configurando a juventude como categoria sociológica.

CASTRO e AQUINO (2008) afirmam que a política social de juventude se consolida ao longo da década de 1990, com o ECA, e tem um papel decisivo na conformação e afirma que "deste novo contexto ideológico, em que emerge a compreensão dos jovens como sujeitos de direitos, definidos não mais "por suas incompletudes ou desvios", mas por suas especificidades e necessidades, que passam a ser reconhecidas no espaço público como demandas cidadãs legítimas. A partir dos anos 90, há uma preocupação mais sistemática dos governos brasileiros, em formular e implementar políticas especificas voltadas para os jovens, com vistas a um diálogo com outras políticas sociais.

Novas práticas de políticas públicas são direcionadas a infância a fim de reconhecer a juventude como um ator estratégico em desenvolvimento, mudando os desenhos institucionais e a relação com outras políticas setoriais na 
sociedade brasileira. Inicia-se no âmbito governamental novas propostas de políticas de juventude relacionadas à promoção social, permitindo e delimitando jovens em situação de risco social e beneficiários de programas de transferência de renda, como público alvo, reconhecendo o jovem como "individuo em desenvolvimento".

No início da presente década, inúmeras iniciativas públicas, muitas envolvendo parcerias com organizações não governamentais (ONGs), fundações empresariais e as várias instâncias do Poder Executivo, que são mobilizadas, tanto no nível federal como no estadual e municipal. SPOSITO (2003) destaca que grande parte destes programas tinha como foco os jovens excluídos ou, na condição que se tornou usual conceitualizar, como de risco social e que em muitas de suas formulações a condição juvenil era apresentada como um elemento problemático em si mesmo, demandando, desta forma, estratégias de enfrentamento dos problemas da juventude.

Prevaleceram políticas focalizadas em setores que apresentam as características de vulnerabilidade, risco ou transgressão - normalmente, os grupos visados encontravam-se na juventude urbana, pobre e negra. De forma geral, eram iniciativas pontuais de curta duração e voltadas para a inclusão social de jovens via oficinas de capacitação, visando melhorar a inserção no mundo do trabalho. Entretanto não foi organizada em nível de política nacional, mais o inicio da organização de grupos juvenis com representação em variados campos - cultural, esportivo, ambiental, estudantil, político-partidário, movimentos étnicos e em prol da igualdade de gênero, associações de bairro, entre outros, que pressionavam o poder público a reconhecer os problemas específicos que os afetavam e a formular políticas que contemplassem ações para além daquelas que apenas viam os jovens como sinônimos de problema.

Em 2004, inicia-se no Brasil um amplo processo de diálogo entre governo e movimentos sociais sobre a necessidade de se instaurar uma política de juventude no país, que segundo SPOSITO (2005), o desafio estava em planejar políticas que, por um lado, "visassem à garantia de cobertura em relação às diversas situações de vulnerabilidade e risco social apresentadas para os jovens e, por outro, buscassem oferecer oportunidades de experimentação e inserção social múltiplas, que favorecessem a integração dos jovens nas várias esferas sociais". (SPOSITO, 2005).

A fragilidade institucional, a fragmentação e a superposição das políticas federais de juventude, percebe-se a urgente necessidade de criação de uma instância de coordenação e de articulação, que tivesse, entre outras atribuições, a de combater o paralelismo e a fragmentação das ações federais dirigidas ao público jovem, iniciando a construção de uma política que contemplasse os desafios vistos no diagnostico para a pauta na Política Nacional de Juventude. Os argumentos da racionalidade técnica e da melhoria de gestão, que resultariam na possibilidade de atender maior número de jovens sem que fosse necessário aumentar os recursos na mesma proporção, são descartados frente ao forte 
apego institucional que leva diferentes órgãos e forças políticas representadas a competir entre si pela marca de programas próprios e pelas diferentes formas de atuação e gestão. Por questões dessa natureza, no fim do processo de discussões e avaliação, não houve extinção de programas e as ações anteriores foram abrigadas sob a denominação de um único nome: Pro Jovem Integrado, que foi lançado em setembro de 2007.

\section{O Projovem Adolescente: análise de sua implementação em}

\section{Contagem}

O Pro Jovem Adolescente é um serviço socioeducativo, gerido pelo Ministério do Desenvolvimento Social e Combate à Fome, é uma reformulação do Projeto Agente Jovem e destina-se aos jovens de 15 a 17 anos: i) pertencentes a famílias em condição de extrema pobreza e beneficiárias do Programa Bolsa Família (PBF); ii) egressos de medida socioeducativa de internação ou em cumprimento de outras medidas socioeducativas em meio aberto; iii) em cumprimento ou egressos de medida de proteção; iv) egressos do Programa de Erradicação do Trabalho Infantil (Peti); ou v) egressos ou vinculados a programas de combate ao abuso e à exploração sexual.

Seus objetivos declarados são complementares para a proteção social básica à família, criando mecanismos para garantir a convivência familiar e comunitária e criar condições para inserção, reinserção e permanência do jovem no sistema educacional. O programa oferece atividades socioeducativas durante 24 meses. Sua gestão está relacionada à secretaria de Assistência Social dos municípios.

O município de Contagem aderiu a implementação do programa no ano de 2008, tendo destaque sobre a singularidades especificas entre os municípios, no que se refere a gestão compartilhada. O município da pesquisa se localiza na região metropolitana de Belo Horizonte, tendo como referência para a implantação de programas na área de juventude e assistência social, os índices de criminalidade enfrentados na região.

Outro norte percussor que nos levam ao entendimento destas relações, implicadas no processo de gestão e gerenciamento das políticas públicas, dentro dois quais nos permite diagnosticar a continuidade destas ações a partir da ausência técnica e operacional do poder local, e caracterizada por FRANCO(2003), como uma fragilidade dos agentes participantes deste processo, no que se refere a sua capacidade técnica operacional, dentro de limitações técnicas financeiras a partir do reconhecimento dos papeis do poder público e das ONGs executoras. 
Esses direcionamentos ainda nos levam a perceber sobre a dissonância entre a gestão social normativa do programa, localizada a nível federal, a gestão social local, estabelecida pelo poder local a partir das demandas e realidades municipais e a gestão institucional do programa, esta estabelecida entre as organizações não governamentais executoras, tal como afirma ( SOUZA, 2007).

Neste sentido aliamos o conceito que DRAIBE (1997), conceitua como a dissonância e a ausência de políticas coordenadas de descentralização, a partir de dois fenômenos indesejados nas políticas públicas: a fragmentação ou estilhaça mento dos programas sociais, que a se refere para além de sua flexibilização e atomização local e o reforço do poder das estruturas centrais, descaracterizando o papel de controle social.

A abordagem metodológica escolhida para esta análise dos dados da pesquisa é qualitativa que privilegia a análise de micro processos por meio do estudo das ações sociais, individuais e grupais utilizando o método qualitativo. Este método, segundo Bauer e Gaskell (2003), implica em um direcionamento próprio por meio da construção de dados descritivos, que permite que o pesquisador entenda o processo e a interação dos fenômenos sociais num dado objeto de estudo.

Este trabalho se concentrou na construção de categorias de análise em torno da relação dos atores envolvidos no processo - as ONGS - e a administração pública municipal. A escolha dos informantes para a pesquisa foi realizada pela organização e estruturação do programa no município, assim como a identificação do envolvimento de cada um no processo de implementação. Identificou-se 3 (três) segmentos importantes que fizeram a composição desta amostra: os gestores municipais, os gestores de organizações não governamentais e os técnicos sociais que atuam nos Centros de Referência da Assistência Social (CRAS), no qual realizam o acompanhamento do programa no governo municipal. A título de esclarecimento, a não realização de entrevistas com o adolescente público-alvo do programa, se difere pela análise que essa pesquisa procurou fazer, pois, o foco é discutir a relação entre governo local e as ONGs e a relação entre estes implementadores institucionais do programa.

No total foram entrevistadas 20 (vinte) pessoas sendo: 2 (dois) gestores municipais, 10 (dez) gestores de ONGS e 8 (oito) técnicos sociais do CRAS, entre psicólogos e assistentes sociais que atuam no serviço. A identificação das instituições executoras foi feita por meio da SMDS. A relação dos técnicos participantes da pesquisa foi realizada de acordo com a localização dos CRAS, onde cada técnico atuava no acompanhamento do programa após autorização prévia da SMDS.

As entrevistas realizadas com os gestores das ONGs tiveram como objetivo abordar questões sobre o interesse da instituição na execução do programa, os critérios necessários para a habilitação da instituição para a implementação do programa, questões acerca da forma de gestão interna do Projovem, as formas 
de participação no processo de implementação, dificuldades encontradas neste processo, assim como a definição de papéis em todo o ciclo do programa em questão. As entrevistas com os gestores governamentais tiveram o propósito de compreender o processo de implementação do programa pela administração local, compreensão dos critérios para a seleção das instituições envolvidas, participação entre entes federados (diálogo entre União e Município), formas de gestão e controle social do programa, acompanhamento da operacionalização do mesmo na fase de implementação, a identificação dos problemas gerados pelo desenho do programa, e as dificuldades encontradas para sua implementação. Por sua vez, as entrevistas realizadas com os técnicos dos CRAS, tiveram como objetivo identificar as questões sobre o acompanhamento (suas diretrizes), suas responsabilidades e atribuições na implementação do programa, assim como alguns problemas identificados no acompanhamento indireto do programa.

Inicia-se esta reflexão com a contribuição de Odriozola (2008), que afirma que os países vêm desenvolvendo novas estratégias de inserir a sociedade civil na gestão de políticas públicas, tendo modelos de colaboração diversas, que segundo a autora vão se reinventando e mudando de acordo com seus motivos e os objetivos a serem alcançados. O trabalho conjunto entre Estado e Terceiro Setor é chamado pela autora de co-gestão. No estudo de caso apresentado, a responsabilidade de formulação da política pública é da União, que por sua vez transfere aos municípios a implementação, e estes apresentam ter uma frágil capacidade de gestão pública, e que por sua vez transferem a execução para as instituições locais. O estudo contribui para pensarmos que existe de fato uma ausência de diálogo entre entes federados na tomada de decisão para as ações locais, além de pressupor uma homogeneidade nas capacidades de gestão dos municípios que integram a federação. Este desenho não é encontrado somente no caso do Projovem, mas sim nos programas executados por instituições não governamentais em diversas áreas de políticas públicas.

Quando há abertura de execução em parceria com esta chamada sociedade civil na implementação dos programas sociais, pressupõe-se que há continuidade da desresponsabilização do Estado como o principal executor e garantidor das ações das políticas sociais. Destaca-se ainda que quando o estado reproduz as características do modelo neoliberal, que ao invés de ampliar, reduz sua função de proteção social, tem como consequência a terceirização do acesso aos bens e serviços públicos.

Outro elemento encontrado no estudo de caso é a ausência de critérios para a seleção das instituições executoras. O marco legal do terceiro setor e a normativas operacionais das políticas públicas não apresentam uma regulação especifica sobre os critérios estabelecidos para a seleção das instituições. Em torno desta questão, Odriozola (2008) afirma que a participação associativa nas políticas públicas amplia possibilidades de gerar um novo ator que participa do controle e do monitoramento da administração pública, ou da imersão de grupos com maior influência nas decisões políticas, relativas à execução de programas governamentais. 
Esta participação associativa, destacada pela autora, se vincula ao papel de controle social dos atores envolvidos. Entretanto o estudo de caso apresentado, mostrou que há uma limitação para este controle social, pois as mesmas entidades executoras são as mesmas conselheiras que deliberam a política pública. Todavia tais pressuposto se relacionam as considerações acerca do esvaziamento da representação da sociedade civil, em seus conteúdos classistas, remetendo aos interesses atomizados e individuais de sua representação.

Entretanto, tomando-se em conta o estudo de caso, nota-se que em Contagem há uma excessiva discricionariedade do governante local, a qual justifica suas escolhas pelas oportunidades, a conveniência pessoal e o interesse público sintetizados no chamado mérito do ato administrativo. Isto revela uma fragilidade de participação associativa nas políticas públicas. O estudo demonstra, contudo, que isto não é um fator que inquieta as entidades executoras, mas que pode ser objeto de reflexão a um oportuno estudo.

Considera-se que a ampliação da participação da sociedade civil na escolha das instituições executoras, aliada a uma legislação a nível federal, que seja pautada em critérios técnicos e operativos para a execução dos programas, contribuiria para adoção e manutenção de práticas impessoais, relevando os critérios técnicos operativos para a gestão pública local, conseguindo ir além dos "muros da pessoalidade". Ao propor que a capacidade de gestão seja dos atores da sociedade civil através das entidades executoras, o Estado continua a se desresponsabilizar de sua função de gestão pública local, se não considerar as fragilidade e limitações dos agentes participantes no processo de implementação, pelas suas capacidades especificas dentre elas: técnica, operacional e financeira.

Outros problemas devem ser apontados: falta de definição das competências operacionais, sobrecarga de ação por outro ator governamental e não governamental, divergências entre as demandas locais e o desenho proposto pelo programa, e a efetividade das ações. Foram observados na pesquisa alguns elementos que se relacionam com os aspectos citados, tais como a rotatividade dos usuários no programa, o fato de a demanda dos jovens ser diferente da oferta proposta pelo programa, vínculos trabalhistas precários dos trabalhadores do programa em função do modelo de execução proposta, ausência de mecanismos de avaliação e monitoramento do programa em nível local.

Tais elementos levam a afirmar que no município de Contagem, na implementação do programa Projovem, a relação entre ONGs e governo local está longe de ser virtuosa e efetiva co-gestão como propõem diversos autores ao referir-se à atuação do terceiro setor nas políticas sociais.

Referente à questão da operacionalidade do programa, os informantes das instituições não governamentais destacaram que foram insuficientes para o início do programa. Nos discursos deles, encontraram ainda motivações pessoais para 
a execução e a formatação do projeto de forma interna. Os gestores municipais ressaltaram que a ausência de uma formatação mais específica possibilitou várias interpretações do programa, ações diferenciadas, chamando a atenção no que eles afirmam ser as ONGs que fazem a "cara do programa", inserindo o caráter da autonomia entre elas.

Percebe-se que a "autonomia relativa", destacada anteriormente pelo gestor municipal, é maior, considerando nas formas de gestão que as instituições não governamentais têm. Esta autonomia relativa, considerando o discurso do gestor municipal, em um primeiro momento, poderia envolver um diálogo maior quanto à execução do serviço, entretanto por ser executada em diversos espaços, elas passaram a ter outro contexto, ou seja, envolve a gestão das ONGs, se relacionando com o fato do poder público repassar a estas a autonomia e ao mesmo tempo, contribuindo para uma desresponsabilização na execução, uma vez que as ONGs ficam responsáveis por toda a gestão interna do programa.

Entre os destaques dos informantes, estão alguns elementos sobre a ausência de informações prévias sobre o programa, os serviços que (muitas vezes, segundos os informantes) prejudicavam as informações e não houve uma capacitação técnica vinda do MDS para os técnicos que iriam atuar no acompanhamento do programa, essas informações eram somente da SMDS. Os informantes avaliaram que, o que era a cargo da SMDS ela conseguia responder e o que ia além do desenho do programa, ficava com informações fragilizadas.

Alguns técnicos destacaram que algumas instituições agiram com pouca receptividade ao repassar às informações sociais dos adolescentes, mas no que diz respeito aos encaminhamentos feitos pelas entidades, os técnicos afirmaram que buscavam relacionar todos. Alegam que no momento de preparação das atividades, a função do CRAS era também de participar, uma vez que a ação da entidade era realizada, estava no território referenciado pelo CRAS e o serviço era da política da assistência social.

A mesma questão é observada junto aos gestores das ONGs que pela questão da indefinição das responsabilidades, muitas vezes as equipes técnicas das instituições fazem o que deveria ser feito pelos CRAS, tal como o acompanhamento social dos jovens e o contato com as famílias deles. Entre os aspectos observados nas entrevistas do CRAS e também presentes nos discursos dos gestores municipais e das ONGs, está a ausência clara da definição de competência na implementação do programa. É possível identificar quando o poder público que nem o gestor municipal, nem os técnicos dos CRAS, nem os gestores das ONGs têm a clareza nos papéis a serem desenvolvidos por cada um.

Entre estas questões de ausência de competências está a questão do acompanhamento junto as ONGs, que somente é realizado pelos CRAS através de uma reunião local nas entidades, iniciadas desde o final de 2008. Porém, algumas questões como a dificuldade de acompanhar in loco as ações, são apontadas pelos técnicos dos CRAS. Segundo os técnicos, a única forma de 
realizar este acompanhamento é por meio das reuniões locais que acontecem quinzenalmente nas instituições, no qual participam orientadores sociais que atuam diretamente com o jovem onde são propostas as atividades e elas são repassadas nos CRAS.

A questão da ausência das competências destaca-se os itens que envolvem a compreensão tanto dos gestores das organizações quanto aos gestores públicos:

Tantos os informantes municipais, quanto os informantes das entidades executoras destacaram nas entrevistas questões que decorrerem dessa ausência na definição dos papéis, ausência no diálogo e a questão do próprio desenho do programa que impactam diretamente na efetividade do programa aos jovens atendidos. Dentre elas enfatizam-se: O público referenciado pelo programa tem características de vulnerabilidade e risco social, o que de certa forma reduz sua condição de acesso a oportunidades no campo de trabalho e escolar entre outros. O programa nos eixos trabalhados, por se tratar de uma faixa etária, se insere em atividades socioeducativas, que muitas vezes não são atrativas para os jovens que participam; A ausência de uma formação no serviço no campo do trabalho reduz as expectativas do jovem em participar do projeto, fazendo com que esteja relacionado muito mais no campo do lazer do que no educativo; Ausência de uma preparação para a formação ao trabalho dos jovens com a faixa etária do serviço, sem perspectivas de remuneração, considerando que não é o caráter do Projovem, faz com que muitos dos participantes deixem de participar do programa e se insiram em atividades precárias de trabalho remuneradas; Os entrevistados destacaram que o desenho do programa não se alia com o perfil do público atendido, ou seja, as atividades que são oferecidas muitas vezes não se relacionam com as expectativas vivenciadas por eles. Afirmam que lidam com o problema de rotatividade do público atendido e que a metodologia do traçado metodológico, implica que o adolescente participe durante 3(três) anos e não consiga ser atendido em suas necessidades.

Outro destaque é sobre a precariedade dos recursos envolvidos na execução das atividades, pois, grande parte dos recursos humanos que atuam no serviço, têm vínculos de trabalho terceirizados, acarretando em baixos valores de remuneração e uma grande rotatividade destes envolvidos, e acarreta como resultados uma ausência de sequência na execução do serviço, sendo consequência deste modelo de gestão.

\section{Considerações Finais}

Observa-se que a representação de que a sociedade civil participa das políticas já é assunto encerrado, ficou passiva a questionamentos. Há quem 
afirme tratar-se de um tema fora de moda, justificando assim a falta de interesse dos cientistas sociais brasileiros sobre as associações público-privados nas políticas sociais. Porém, ao longo desta construção, observou-se que este tema é muito atual e mereceria maior atenção nos estudos de politicas públicas. Considera-se ainda que este não seja um problema que se limita somente ao município estudado, mas a toda diversidade territorial existente no contexto brasileiro. A hipótese de que os programas sociais são entregues para execução das entidades privadas, pois o Estado por sua vez não tem capacidades operacionais para executá-lo, se confirma no estudo de caso. Além disso, o poder local apresenta baixa capacidade para acompanhar e regular a execução do programa pelas entidades não governamentais.

Também se confirma que o poder público não está convicto quanto ao papel ou potencial das ONGs em seu caráter de inovação, participação e conhecimentos mais próximos e a forma mais próxima da população. Verifica-se ainda que a descentralização não seja em si mesma, uma alternativa de reconhecimento das diversidades com expectativas de atender as demandas locais, pois, uma vez que ao tentar generalizar a formulação das políticas públicas de forma geral (da União para os municípios) elas ficam engessadas parar seus fins. Quanto aos conselhos gestores no caso de Contagem, percebeuse que seu papel de controle social na implementação do Programa Projovem, é frágil, tendo como consequência uma ausência de regulação entre a sociedade civil e o governo local tal como exposto acima. Esta questão se confirma quando se percebe que os agentes que deveriam realizar o controle social da política, são os mesmos que a executa.

Relaciona-se a esta questão o esvaziamento da sociedade civil, contida em sua pluralidade de interesses atomizados, provocando uma luta delimitada como intra-classes, ao invés de luta entre classes, acarretando a ampliação de um debate genérico sobre democracia e cidadania. Ao tempo que há uma fragilidade no controle social, pelo esvaziamento do papel da sociedade civil, a compreensão de poder local como o conjunto de forças sociais, também se limita, pois exime o Estado de seu papel como executor, não considera os atores presentes no local e por sua vez, não buscam uma ampliação dos canais para a promoção da gestão social local. A discussão apresentada sobre juventude se relaciona com as questões históricas trazidas no trabalho, fazendo com que este segmento populacional seja objeto de intervenção de várias políticas, mas nenhuma se responsabiliza por tal. Percebe-se que as mudanças de perspectivas das políticas sociais de juventude, como o paradigma de problemas sociais ainda permeia as relações existentes no Estado.

O estudo de caso apresentado sobre o município Contagem considerou que os fatores históricos que se referem à ausência de atuação e representação dos movimentos sociais são ainda componentes importantes para a lentidão de avanços da gestão pública municipal, permitindo ainda pensar que é necessário desconstruir a lógica existente na atualidade de que a implementação de políticas públicas deve acontecer por meio de caixinhas prontas, das quais a 
administração local fica impossibilitada de intervenção e mudanças necessárias para adequar à sua realidade. Ao considerar o lugar da implementação de políticas como um elo perdido na análise de políticas públicas, este trabalho visou destacar a importância do diálogo entre os atores envolvidos neste processo considerando esse fator um elemento chave para o alcance dos propósitos das políticas sociais e para a efetiva construção do poder local.

Reafirma-se a necessidade de busca por novas alternativas de gestão que privilegiem a vocalização do maior número de atores sociais, tanto no planejamento, quanto nos processos e nos meios. Nesse aspecto, ressalta-se o lugar de protagonismo que os atores das políticas públicas devem ocupar na agenda política, atentos à ausência, conveniência ou fragilidade de articulação na implementação, possibilitando caminhos que consigam romper com a história de reprodução presente. Demandas e necessidades devem se tornar prioridade na agenda pública governamental, tornando-se interesse também do Estado e não apenas dos grupos organizados da sociedade, fazendo com que o primeiro garanta a qualidade e efetividade dos serviços executados de forma indireta.

\section{Referencias Bibliográficas}

Abrucio, Fernando Luiz., \& Couto Cláudio Gonçalves. (1996). “A redefinição do papel do Estado no âmbito local". São Paulo em Perspectiva, São Paulo, v. 10, n.3, p. 40-47, jul/set.

Arretche, Marta T. S. (1999). "Políticas sociais no Brasil: descentralização em um Estado federativo". Revista Brasileira de Ciências Sociais, São Paulo, v. 14, n. 40, p. 111-141.

Bauer, Martin W., \& Gaskell, George. (2002). “Pesquisa qualitativa com texto imagem e som: um manual prático". 2. ed. Petrópolis: Vozes.

Behring, Elaine Rossetti; Boschetti, Ivanete. (2008). (Org.) "Política Social no Capitalismo Tardio: Tendências Contemporâneas". 2. ed. São Paulo: Cortez.

Bresser-Pereira, Luiz C. (1996). “A Administração Pública Gerencial: estratégia e estrutura para um novo Estado". Brasília, ENAP.

Carvalho, Maria do Carmo Brant. (2003). “Gestão Social: alguns apontamentos para o debate". Em: Rico, Elizabeth de Melo; Raichelis, Raquel (Org). Gestão Social: uma questão em debate. 1.ed. São Paulo: EDUC; IEE, p. 19-29.

Castro, Jorge A. \& Aquino, Luseni. (2008). (orgs.). “Juventude e Políticas Sociais no Brasil. Texto para Discussão". N0 1335. Brasília: Instituto de Pesquisa Econômica Aplicada (Ipea). 
Draibe, Sônia. (2003). "A política social no período FHC e o sistema de proteção social. Revista Tempo Social”. São Paulo, v. 15, n. 2, p. 63-101, jan/abr.

Farah, Marta Ferreira Santos. (2006). "Parcerias Novos Arranjos Institucionais e Políticas Públicas no Nível Local de Governo". Cadernos Gestão Pública e Cidadania, São Paulo, v.18, abr.

Filgueiras, Cristina Almeida Cunha., Caetano, André Junqueira. (2008). “Programa Federal, execução local: o caso da Bolsa Família". In: FILGUEIRAS, Cristina Almeida Cunha; FARIA, Carlos Aurélio Pimenta. Governo Local, política pública e participação na América do Sul. Belo Horizonte: PUC Minas.

Fleury, Sonia. (2005). "A seguridade social e os dilemas da inclusão social". Revista de Administração Pública. Rio de Janeiro, v. 39, n. 3, p. 449-69, maio/jun.

Grau, Nuria Cunill; Pereira, Luiz Carlos Bresser. (1998). “Lo Público No-Estatal en la Reforma de lo Estado". Buenos Aires: Editorial Paidós.

Odriozola, Cecilia Rossel. (2008). "Tercer Sector y co- gestión de politicas en España y Uruguai: Un Matrimonio por conveniencia?". España: INAP Instituto Nacional de Administracion Publica.

Pereira, Potyara. (2008). “Política Social: Temas e questões". 2.ed. São Paulo: Cortez.

Pierre, Jon., \& Stoker, Gerry. (2001). “Towards multi-level governance". In: Dunleavy, Patrick. Developments in British Politics, London, v. 29, n. 2, p. 131-135.

Souza, Celina. (2006). "Políticas Públicas: Uma Revisão de Literatura". Sociologias, Porto Alegre, n.16, p.20-45, jul./dez.

Souza, Celina. (2008). "Federalismo: Teorias e Conceitos revisitados". Revista Brasileira de Informação Bibliográfica em Ciências Sociais, São Paulo, v. 65, p. 27-48.

Sposito, Marilia., e cols. (2007). "Espaços públicos e tempos juvenis". Um estudo sobre ações do poder público em cidades de regiões metropolitanas brasileiras. São Paulo: Global.

Sposito, Marilia. (2003). "Algumas reflexões e muitas indagações sobre as relações entre juventude e escola no Brasil". Em Abramo, Helena., e Branco, Pedro Paulo. Retratos da juventude brasileira: análises de uma pesquisa nacional. São Paulo: Instituto da Cidadania/Editora Fundação Perseu Abramo. p. 129-148. 
Recebido em 26/06/2012 Aceito em 12/10/2015 